\title{
Untangling the $\mathrm{T}$ branch of the Hematopoiesis Tree
}

\author{
Anthony W. Chi, J. Jeremiah Bell, Daniel A. Zlotoff, and Avinash Bhandoola \\ Department of Pathology and Laboratory Medicine, University of Pennsylvania School of Medicine, \\ Philadelphia, PA 19104, USA
}

\section{Summary}

$\mathrm{T}$ cells develop in the thymus. Previous work suggested an early separation of lymphoid from myeloerythroid lineages during hematopoiesis, and hypothesized the thymus was settled exclusively by lymphoid-restricted hematopoietic progenitors. Recent data have instead established the existence of lymphoid-myeloid progenitors, which possess lymphoid and myeloid lineage potentials but lack erythroid potential. Myeloid and lymphoid potentials are present at the clonal level in early thymic progenitors, confirming that progenitors settling the thymus include lymphoid-myeloid progenitors. These results revise our view of the $\mathrm{T}$ lineage branch of hematopoiesis, and focus attention on the generation, circulation, and homing of lymphoid-myeloid progenitors to the thymus.

\section{Introduction}

$\mathrm{T}$ cells are unique among blood cells, as they require a dedicated organ for their development, the thymus. Progenitors in the thymus lack self-renewing capacity, and so T lymphopoiesis requires periodic import of hematopoietic progenitors from the blood. These progenitors must leave the bone marrow (BM), traffic through the circulation, and settle the thymus before developing into mature $\mathrm{T}$ cells.

In this review, we describe differences between past and revised models of $\mathrm{T}$ lineage development in adult mice. We discuss developmental potentials of early thymic progenitors (ETPs), as they represent the most immature thymocytes identified so far. We describe extrathymic progenitors that are candidate sources of $\mathrm{T}$ cell progenitors, with an emphasis on thymus homing ability. We summarize recent advances in identifying thymus-settling progenitors as the link between BM and the thymus in T lymphopoiesis.

\section{Two models of $\mathrm{T}$ lineage development}

All blood cell types originate from multipotent, self-renewing hematopoietic stem cells (HSCs), via non-renewing multipotent progenitors (MPPs), but developmental steps downstream of MPPs are less well understood (Figure 1). One model of hematopoiesis proposed a strict separation of lymphoid and myeloerythroid lineages [1]. This idea was supported by the identification of common myeloid progenitors (CMPs) and common lymphoid progenitors (CLPs) in BM [1]. Implicit in this model was the notion that the thymus is settled by lymphoid-restricted progenitors with developmental potential for T, B, and NK lineages. However, current data suggest a revised model in which erythroid potential is lost but myeloid potential is retained in progenitors of lymphocytes (Figure 1). This is supported

Correspondence: Avinash Bhandoola; E-mail: bhandooa@mail.med.upenn.edu.

Publisher's Disclaimer: This is a PDF file of an unedited manuscript that has been accepted for publication. As a service to our customers we are providing this early version of the manuscript. The manuscript will undergo copyediting, typesetting, and review of the resulting proof before it is published in its final citable form. Please note that during the production process errors may be discovered which could affect the content, and all legal disclaimers that apply to the journal pertain. 
by strong evidence for the existence of progenitors that have lost erythroid potential but retain lymphoid as well as myeloid potentials (LMPs) [2-6]. In the revised model, the thymus is settled by such lymphoid-myeloid progenitors. One job of the thymus is therefore to restrict such multipotential progenitors to the $\mathrm{T}$ cell lineage.

\section{Early thymic progenitors (ETPs)}

The precise identity of hematopoietic progenitors that settle the thymus is difficult to know with certainty, due to the fact that many extrathymic progenitors possess $\mathrm{T}$ lineage potential and only a few cells are needed to settle the thymus for robust thymopoiesis [7]. Consequently, identifying and characterizing the most immature thymocytes with $\mathrm{T}$ lineage potential in the thymus has been a focus of many laboratories, as these cells might represent the thymus-settling progenitors or their immediate progeny. Early studies demonstrated that cells with a $\mathrm{CD} 4^{-/ \text {low }} \mathrm{CD}^{-} \mathrm{CD}^{-} \mathrm{CD} 25^{-} \mathrm{CD} 44^{+}$surface phenotype (termed double-negative 1 or DN1) were the least mature thymocytes [7]. Further examination of this population showed that efficient $\mathrm{T}$ lineage progenitor activity resides in the $\mathrm{Kit}^{+}$subset, which lacks surface markers associated with terminally differentiated blood lineages. These efficient $\mathrm{T}$ cell progenitors are termed early thymic progenitors (ETPs, minimally defined as $\mathrm{Lin}^{-} \mathrm{CD} 25^{-} \mathrm{Kit}^{+}$) and constitute approximately $0.01 \%$ of the young adult mouse thymus [7-11]. ETPs have been referred to as "canonical" $\mathrm{T}$ cell progenitors because of their tremendous efficiency in generating downstream DN2 $\left(\mathrm{CD} 25^{+} \mathrm{Kit}^{+}\right), \mathrm{DN} 3\left(\mathrm{CD} 25^{+} \mathrm{Kit}^{-}\right)$, and double-positive $\left(\mathrm{CD} 4{ }^{+} \mathrm{CD} 8^{+}\right) \mathrm{T}$ lineage progeny $[10,11]$ (Figure 2). ETPs are themselves heterogeneous for expression of several surface markers, including CD24, Flt3, and CCR9, suggesting the existence of developmental transitions even within this rare progenitor population [11-13]. Flt3 ${ }^{+}$ETPs represent a small subset of ETPs, and overlap with the EGFP-brightest subset of ETPs in CCR9EGFP reporter mice [12-14]. This subset of ETPs appears more primitive than others that lack expression of the Flt3 receptor [12].

\section{The ability to constrain alternative lineage cell fates by the thymus}

The majority of ETPs retain developmental potentials for NK and DC lineages at the clonal level [13-20]. Rare ETPs within the Flt $3^{+} \mathrm{CCR}^{+}$subset can also give rise to B cells; however, the vast majority of ETPs lack B potential [11-14,20]. Most recently, it has been shown that ETPs possess myeloid potential $[19,20]$ in clonal assays $[17 \bullet \bullet, 18 \bullet \bullet$. Downstream of ETPs, some DN2 cells can still give rise to NK, DC and myeloid cells, but most are committed to the T cell lineage [15-18••]. The T cell fate is further consolidated at the DN3 stage, where developmental potential for alternative lineages is completely lost.

The presence of non-T lineage potentials in ETPs necessitates mechanisms within the thymus that promote the $\mathrm{T}$ cell fate while inhibiting development of alternative lineages. Recently Delta-like 4 was shown to be expressed in thymic epithelial cells and responsible for activating Notch1 signaling in incoming progenitors $[21 \bullet, 22 \bullet]$. In DN3 thymocytes, Notch1 acts as a trophic factor, ensuring growth, proliferation and survival [23]. In ETPs, however, Notch1 signaling is likely required to restrict progenitors to the $T$ cell fate, as withdrawal of Notch1 signals in ETPs leads to development of alternative lineages [6,24]. Mechanisms downstream of Notch1 signaling that direct lineage restriction are currently not well understood.

\section{Multi-lineage Hematopoiesis in the Thymus}

Despite evidence for active Notch1 signaling in ETPs [12,25], cells of alternative lineages are generated from ETPs in the thymus. Early work showed that intrathymic T progenitors could give rise to thymic dendritic cells (DC) [26]. Some natural killer (NK) cells in the periphery were found to express rearranged TCR $\gamma$ genes; these rearrangements could not be detected in NK cells of athymic nude mice, suggesting some NK cells develop in the thymus [27,28]. The 
thymus is also estimated to produce and export approximately $2 \times 10^{4}$ mature B cells daily [29]. Most recently, thymic granulocytes and macrophages have been shown to arise from ETPs, further establishing that thymic settling progenitors possess myeloid lineage potential among their non-T lineage potentials, and that this potential is realized in the thymic niche $[17 \bullet \bullet, 18 \bullet \bullet]$. How some ETPs escape the T cell fate to instead generate NK and myeloid cells, and possibly cells of other lineages, awaits further investigation.

\section{Multiple extrathymic progenitors with $\mathrm{T}$ lineage potential}

Notch1 signaling is necessary for $\mathrm{T}$ lineage development [30]. Thus, progenitors with $\mathrm{T}$ lineage potential must be able to express Notch1 receptors and respond to Notch1 inductive signals. Several progenitors in adult mouse BM express Notch1 and possess T lineage potential, including HSCs. The most primitive hematopoietic progenitors reside within a rare subset that bears the "LSK" phenotype $\left(\mathrm{Lin}^{-} \mathrm{Sca}-1^{+} \mathrm{Kit}^{+}\right)$. This LSK pool is heterogeneous and contains multipotent and self-renewing HSCs, non-self-renewing MPPs, and also early lymphoid progenitors (ELPs) that are lymphoid-specified since they express lymphoid-specific genes such as RAG1 and RAG2 [4,5]. ELPs are efficient lymphoid progenitors, but retain myeloid lineage potential [5]. They overlap extensively with a population of LSK progenitors expressing the highest levels of Flt3, which are named lymphoid-primed multipotential progenitors or LMPPs [4] - we use ELP and LMPP terms interchangeably in this review.

Several progenitors outside of the LSK pool also possess T lineage potential, including common lymphoid progenitors (CLPs) as well as early progenitors with lymphoid and myeloid developmental potential (EPLMs) that overlap with common lymphoid progenitors-2 (CLP-2) cells $[1,31,32]$. Krueger and von Boehmer have reported a $\mathrm{T}$ lineage-biased progenitor in the blood, which they termed circulating T cell progenitors (CTPs) [33]. An independent group earlier reported a rare population in BM, also named CTPs for committed $\mathrm{T}$ cell progenitors [34]. Both CTPs share a similar phenotype; a developmental relationship between these cells and phenotypically similar cells in spleen has been suggested [35]. Surface phenotypes of these progenitors have been recently reviewed [36] and are not repeated here. Most recently, a subpopulation of BM cells of the $\mathrm{Lin}^{-} \mathrm{Sca}-1^{+} \mathrm{Kit}^{-}$phenotype was shown to also possess $\mathrm{T}$ lineage potential $[37,38]$.

\section{Lymphoid-myeloid progenitors}

As HSCs differentiate towards ELPs, their erythroid potential is lost $[2,4,39 \bullet \bullet, 40]$. Consequently, ELPs are lymphoid-myeloid progenitors. Further downstream, ELPs give rise to CLPs. However, the "CLP" term appears at least in part a misnomer, because myeloid potential remains evident in some "CLPs" and possibly even further downstream in some CLP-2 cells [19,32,37,38,41]; which might indicate heterogeneity within populations previously considered to be lymphoid-restricted. Hence ELPs and a subset of CLPs, as well as additional progenitor cell types, may all represent lymphoid-myeloid progenitors (LMPs, Figure 2) in the BM.

\section{Requirements for generation of lymphoid-myeloid progenitors}

Precursor-successor relationships among progenitors downstream of HSCs are still being charted, but it seems clear that HSCs initially give rise to MPPs, which can differentiate into ELPs and downstream cells (Figure 2). What regulates the transition from MPPs to ELPs is not well understood; however, some critical requirements have been identified. Recent results suggest Wnt 4 signaling may affect these developmental stages, via a non-canonical ( $\beta$-cateninindependent) pathway [42]. In addition, Ikaros has been implicated in generating functional ELPs and CLPs, as these subsets are absent in Ikaros null mice. Flt3 expression within the LSK compartment depends on Ikaros [10,43•]. Perhaps consistent with this observation, Flt3 
signaling is necessary for the generation of ELPs [44,49•]. E2A proteins are crucial for generation of ELPs as well. Similar to Flt3 signaling, E2A transcription factors also upregulate a range of lymphoid-associated genes, while suppressing nonlymphoid genes. In particular, CCR9 and Notch1 expressions in ELPs are controlled by E2A, highlighting its role in generating progenitors competent to home to the thymus and initiate $\mathrm{T}$ cell development $[39 \cdot \bullet, 45]$.

\section{Selective homing of progenitors to the thymus}

For a BM cell to become a successful $\mathrm{T}$ lineage progenitor, it must have the ability to migrate to the thymus. Most of the described progenitors with $\mathrm{T}$ cell potential are known to circulate [46]. The ability of progenitors to settle the thymus, on the other hand, is clearly selective and regulated. A number of chemokine receptors and adhesion molecules have been reported to regulate thymic settling, including CCR7, CCR9, PSGL1, and $\alpha 4$ and $\beta 2$ integrins [47-51]. Among them, the role of CCR9 for optimal homing of prethymic progenitors to the thymus has been repeatedly demonstrated [47-49•,51]. Whether additional molecules are implicated in thymic homing requires further study.

\section{Identification of thymic homing progenitors}

The identification of thymic homing molecules allows a molecular definition of thymic homing progenitors, because any such progenitors must express the necessary complement of molecules required for thymic homing. Interestingly, CCR9 is differentially expressed among the BM progenitors mentioned above. By using CCR9-GFP knock-in mice, Benz and Bluel first reported a group of CCR9 $9^{+}$LSK cells found in both BM and blood [13]. It was later confirmed that these were ELPs $[48 \bullet, 49 \bullet, 52 \bullet \bullet]$.

Indeed, a high frequency of ELPs expresses CCR9, and these progenitors appear efficient in colonizing and repopulating the thymus from the circulation. In contrast, HSCs and MPPs lack CCR9 expression and do not home to the thymus effectively $[48 \bullet, 49 \bullet, 53]$. The most primitive subset of ETPs, the Flt $3^{+}$ETPs, also expresses CCR9 transcripts, and this subset of ETPs is phenotypically very similar to CCR9-expressing ELPs in the bone marrow $[48 \bullet, 52 \bullet \bullet]$. Independent of Notch1 signaling, CCR ${ }^{+}$ETPs have been shown to be the first host progenitor cells appearing within a transplanted thymus [52••]. All these observations support the idea that CCR9-expressing ELPs are likely to represent one type of thymus settling progenitor. However, this is unlikely to represent the full story. In addition to CCR9 $9^{+}$ELPs, other progenitors including CLPs and perhaps CLP-2 cells may also home to thymus and contribute to $\mathrm{T}$ lymphopoiesis $[31,32,37,38,51]$. A contribution from these progenitors seems likely based on the expression of Notch 1 as well as thymic homing molecules on these populations. It further remains possible that $\mathrm{T}$ lineage-committed CTPs also home to the thymus, where they may contribute to T lineage development via a non-canonical pathway that circumvents the ETP step [33,34]. All of these possibilities require further investigation.

\section{Concluding remarks}

T cell development spans multiple anatomic sites. Progenitors with $\mathrm{T}$ potential are generated in the BM and must migrate to the thymus. The classic hematopoietic tree dictated an early separation of lymphoid and myeloerythroid development and proposed that the thymus was settled exclusively by lymphoid-restricted progenitors. Perhaps predictably, things are more complicated. The multiple lineage potentials found in ETPs indicate at least some incoming progenitors must possess myeloid and lymphoid lineage potentials. In line with the revised model (Figure 1), the least mature human thymocyte progenitors also possess myeloid and lymphoid lineage potentials in clonal assays [54]. Downstream of ETPs, developmental potentials for alternative lineages are slowly constrained at least in part by Notch1 signals, and 
finally lost at the DN3 stage. CCR9-expressing ELPs have recently been demonstrated as one possible type of thymus-settling progenitor that gives rise to ETPs. However, it seems plausible that other progenitors may contribute to T lymphopoiesis as well.

The presence of non-T lineage potentials in ETPs raises interesting questions. Is there a reason myeloid and lymphoid lineage potentials are "bundled" together in one group of thymus homing progenitors? Cells of several non-T hematopoietic lineages including dendritic cells, macrophages and granulocytes are present in the adult thymus, and some of these lineages are required for proper thymic function. It seems clear that at least some of these non-T lineage cells arise from ETPs. How are T lymphoid potential as well as alternative lineage potentials of ETPs realized in the thymus? Are some intrathymic niches protected from Notch signaling? Alternatively, might some ETPs express negative regulators of the Notch pathway? In addition to lymphoid-myeloid progenitors, other progenitor types may also migrate to the thymus to help generate non-T cell hematopoietic lineages; such additional progenitors remain to be better identified. Future studies will need to examine how these pathways of T versus accessory cell development in the thymus contribute to $\mathrm{T}$ cell development, and whether these pathways are perturbed in circumstances such as BM transplantation and lymphopenic diseases.

\title{
Acknowledgements
}

We thank D. Allman, A. Sambandam, A. Chavez, S. Cross, A. Tsou, and B. Schwarz for their thoughtful critiques. We apologize to colleagues whose work we were unable to cite because of space limitations.

\author{
Abbreviations \\ CCR9 \\ chemokine (C-C motif) receptor 9 \\ CLP \\ common lymphoid progenitor \\ CMP \\ common myeloid progenitor \\ CTP \\ circulating $\mathrm{T}$ cell progenitor, committed $\mathrm{T}$ cell progenitor \\ DC \\ dendritic cell
}

ELP

early lymphoid progenitor

EPLM

early progenitor with lymphoid and myeloid developmental potential

ETP

early thymic progenitor

HSC

hematopoietic stem cell

LMP

lymphoid-myeloid progenitor

LMPP

lymphoid-primed multipotent progenitor

Curr Opin Immunol. Author manuscript; available in PMC 2010 April 1. 
MPP

multipotent progenitor

NK

natural killer cell

TSP

thymus-settling progenitor

\section{References}

1. Akashi K, Reya T, Dalma-Weiszhausz D, Weissman IL. Lymphoid precursors. Curr Opin Immunol 2000;12:144-150. [PubMed: 10712944]

2. Lu M, Kawamoto H, Katsube Y, Ikawa T, Katsura Y. The common myelolymphoid progenitor: a key intermediate stage in hemopoiesis generating T and B cells. J Immunol 2002;169:3519-3525.

[PubMed: 12244141]

3. Katsura Y. Redefinition of lymphoid progenitors. Nat Rev Immunol 2002;2:127-132. [PubMed: 11910894]

4. Adolfsson J, Mansson R, Buza-Vidas N, Hultquist A, Liuba K, Jensen CT, Bryder D, Yang L, Borge OJ, Thoren LA, et al. Identification of Flt3+ lympho-myeloid stem cells lacking erythromegakaryocytic potential a revised road map for adult blood lineage commitment. Cell 2005;121:295306. [PubMed: 15851035]

5. Igarashi H, Gregory SC, Yokota T, Sakaguchi N, Kincade PW. Transcription from the RAG1 locus marks the earliest lymphocyte progenitors in bone marrow. Immunity 2002;17:117-130. [PubMed: 12196284]

6. Laiosa CV, Stadtfeld M, Xie H, de Andres-Aguayo L, Graf T. Reprogramming of committed T cell progenitors to macrophages and dendritic cells by C/EBP alpha and PU.1 transcription factors. Immunity 2006;25:731-744. [PubMed: 17088084]

7. Shortman K, Wu L. Early T lymphocyte progenitors. Annu Rev Immunol 1996;14:29-47. [PubMed: 8717506]

8. Wu L, Antica M, Johnson GR, Scollay R, Shortman K. Developmental potential of the earliest precursor cells from the adult mouse thymus. J Exp Med 1991;174:1617-1627. [PubMed: 1683894]

9. Matsuzaki Y, Gyotoku J, Ogawa M, Nishikawa S, Katsura Y, Gachelin G, Nakauchi H. Characterization of c-kit positive intrathymic stem cells that are restricted to lymphoid differentiation. J Exp Med 1993;178:1283-1292. [PubMed: 7690832]

10. Allman D, Sambandam A, Kim S, Miller JP, Pagan A, Well D, Meraz A, Bhandoola A. Thymopoiesis independent of common lymphoid progenitors. Nat Immunol 2003;4:168-174. [PubMed: 12514733]

11. Porritt HE, Rumfelt LL, Tabrizifard S, Schmitt TM, Zuniga-Pflucker JC, Petrie HT. Heterogeneity among DN1 prothymocytes reveals multiple progenitors with different capacities to generate $\mathrm{T}$ cell and non-T cell lineages. Immunity 2004;20:735-745. [PubMed: 15189738]

12. Sambandam A, Maillard I, Zediak VP, Xu L, Gerstein RM, Aster JC, Pear WS, Bhandoola A. Notch signaling controls the generation and differentiation of early $\mathrm{T}$ lineage progenitors. Nat Immunol 2005;6:663-670. [PubMed: 15951813]

13. Benz C, Bleul CC. A multipotent precursor in the thymus maps to the branching point of the T versus B lineage decision. J Exp Med 2005;202:21-31. [PubMed: 15983065]

14. Heinzel K, Benz C, Martins VC, Haidl ID, Bleul CC. Bone marrow-derived hemopoietic precursors commit to the $\mathrm{T}$ cell lineage only after arrival in the thymic microenvironment. J Immunol 2007;178:858-868. [PubMed: 17202347]

15. Schmitt TM, Ciofani M, Petrie HT, Zuniga-Pflucker JC. Maintenance of T cell specification and differentiation requires recurrent notch receptor-ligand interactions. J Exp Med 2004;200:469-479. [PubMed: 15314075]

16. Masuda K, Kakugawa K, Nakayama T, Minato N, Katsura Y, Kawamoto H. T cell lineage determination precedes the initiation of TCR beta gene rearrangement. J Immunol 2007;179:36993706. [PubMed: 17785806] 
17••. Wada H, Masuda K, Satoh R, Kakugawa K, Ikawa T, Katsura Y, Kawamoto H. Adult T-cell progenitors retain myeloid potential. Nature 2008;452:768-772. [PubMed: 18401412]

18••. Bell JJ, Bhandoola A. The earliest thymic progenitors for T cells possess myeloid lineage potential. Nature 2008;452:764-767. [PubMed: 18401411]These two papers establish that ETPs possess T and myeloid developmental potential at the single cell level. In addition, myeloid cells isolated from the thymus were found to harbor rearranged TCR $\beta$ genes, and a substantial portion of thymic granulocytes could be lineage-traced back to ETPs. Thymic macrophages were also shown to develop from ETPs. Together with earlier work [2,19,20,41] these observations establish that progenitors settling the thymus include lymphoid-myeloid progenitors.

19. Lu M, Tayu R, Ikawa T, Masuda K, Matsumoto I, Mugishima H, Kawamoto H, Katsura Y. The earliest thymic progenitors in adults are restricted to T, NK, and dendritic cell lineage and have a potential to form more diverse TCRbeta chains than fetal progenitors. J Immunol 2005; 175:58485856. [PubMed: 16237077]

20. Balciunaite G, Ceredig R, Rolink AG. The earliest subpopulation of mouse thymocytes contains potent $\mathrm{T}$, significant macrophage, and natural killer cell but no B-lymphocyte potential. Blood 2005;105:1930-1936. [PubMed: 15522952]

21 • Hozumi K, Mailhos C, Negishi N, Hirano K, Yahata T, Ando K, Zuklys S, Hollander GA, Shima DT, Habu S. Delta-like 4 is indispensable in thymic environment specific for T cell development. J Exp Med 2008;205:2507-2513. [PubMed: 18824583]

22•. Koch U, Fiorini E, Benedito R, Besseyrias V, Schuster-Gossler K, Pierres M, Manley NR, Duarte A, Macdonald HR, Radtke F. Delta-like 4 is the essential, nonredundant ligand for Notch1 during thymic T cell lineage commitment. J Exp Med 2008;205:2515-2523. [PubMed: 18824585]These papers show that whereas Delta-like 1 (DL1) and DL4 ligands are each able to trigger Notch1 signaling and induce T lineage differentiation in vitro, only DL4 is expressed at high levels in thymic epithelial cells, where it is responsible for triggering Notch1 signaling in incoming progenitors. Genetic disruption of DL4 in thymic epithelial cells disrupts intrathymic T cell development in a manner similar to disruption of Notch1. The identification of DL4 as the physiological Notch ligand should allow investigation of intrathymic niches within which progenitors receive Notch signals, and may shed light on mechanisms by which some progenitors escape Notch signaling to give rise to non-T cell lineages within the thymus.

23. Ciofani M, Zuniga-Pflucker JC. The thymus as an inductive site for T lymphopoiesis. Annu Rev Cell Dev Biol 2007;23:463-493. [PubMed: 17506693]

24. Franco CB, Scripture-Adams DD, Proekt I, Taghon T, Weiss AH, Yui MA, Adams SL, Diamond RA, Rothenberg EV. Notch/Delta signaling constrains reengineering of pro-T cells by PU.1. Proc Natl Acad Sci U S A 2006;103:11993-11998. [PubMed: 16880393]

25. Tan JB, Visan I, Yuan JS, Guidos CJ. Requirement for Notch1 signals at sequential early stages of intrathymic T cell development. Nat Immunol 2005;6:671-679. [PubMed: 15951812]

26. Ardavin C, Wu L, Li CL, Shortman K. Thymic dendritic cells and T cells develop simultaneously in the thymus from a common precursor population. Nature 1993;362:761-763. [PubMed: 8469288]

27. Veinotte LL, Greenwood CP, Mohammadi N, Parachoniak CA, Takei F. Expression of rearranged TCRgamma genes in natural killer cells suggests a minor thymus-dependent pathway of lineage commitment. Blood 2006;107:2673-2679. [PubMed: 16317098]

28. Vosshenrich CA, Garcia-Ojeda ME, Samson-Villeger SI, Pasqualetto V, Enault L, Richard-Le Goff O, Corcuff E, Guy-Grand D, Rocha B, Cumano A, et al. A thymic pathway of mouse natural killer cell development characterized by expression of GATA-3 and CD127. Nat Immunol 2006;7:12171224. [PubMed: 17013389]

29. Akashi K, Richie LI, Miyamoto T, Carr WH, Weissman IL. B lymphopoiesis in the thymus. J Immunol 2000;164:5221-5226. [PubMed: 10799882]

30. Radtke F, Wilson A, Stark G, Bauer M, van Meerwijk J, MacDonald HR, Aguet M. Deficient T cell fate specification in mice with an induced inactivation of Notch1. Immunity 1999;10:547-558. [PubMed: 10367900]

31. Martin CH, Aifantis I, Scimone ML, von Andrian UH, Reizis B, von Boehmer H, Gounari F. Efficient thymic immigration of B220+ lymphoid-restricted bone marrow cells with T precursor potential. Nat Immunol 2003;4:866-873. [PubMed: 12925850] 
32. Balciunaite G, Ceredig R, Massa S, Rolink AG. A B220+ CD117+ CD19-hematopoietic progenitor with potent lymphoid and myeloid developmental potential. Eur J Immunol 2005;35:2019-2030. [PubMed: 15971276]

33. Krueger A, von Boehmer H. Identification of a $\mathrm{T}$ lineage-committed progenitor in adult blood. Immunity 2007;26:105-116. [PubMed: 17222572]

34. Garcia-Ojeda ME, Dejbakhsh-Jones S, Chatterjea-Matthes D, Mukhopadhyay A, BitMansour A, Weissman IL, Brown JM, Strober S. Stepwise development of committed progenitors in the bone marrow that generate functional T cells in the absence of the thymus. J Immunol 2005;175:43634373. [PubMed: 16177077]

35. Gautreau L, Arcangeli ML, Pasqualetto V, Joret AM, Garcia-Cordier C, Megret J, Schneider E, Ezine S. Identification of an IL-7-dependent pre-T committed population in the spleen. J Immunol 2007;179:2925-2935. [PubMed: 17709507]

36. Bhandoola A, von Boehmer H, Petrie HT, Zuniga-Pflucker JC. Commitment and developmental potential of extrathymic and intrathymic T cell precursors: plenty to choose from. Immunity 2007;26:678-689. [PubMed: 17582341]

37. Kumar R, Fossati V, Israel M, Snoeck HW. Lin-Sca1+kit- bone marrow cells contain early lymphoidcommitted precursors that are distinct from common lymphoid progenitors. J Immunol 2008;181:7507-7513. [PubMed: 19017940]

38. Harman BC, Northrup DL, Allman D. Resolution of Unique Sca-1highc-Kit-Lymphoid-Biased Progenitors in Adult Bone Marrow. J Immunol 2008;181:7514-7524. [PubMed: 19017941]

39••. Dias S, Mansson R, Gurbuxani S, Sigvardsson M, Kee BL. E2A proteins promote development of lymphoid-primed multipotent progenitors. Immunity 2008;29:217-227. [PubMed: 18674933]The authors show that E2 $\mathrm{A}^{-/-}$mice generate very few ELPs or LMPPs. The few ELPs generated in $\mathrm{E}_{2} \mathrm{~A}^{-/-}$mice are found incapable of upregulating a range of lymphoid-related genes. Interestingly, $\mathrm{E}_{2} \mathrm{~A}^{-/-}$HSCs and MPPs still retain comparable Mk/E potential, whereas E2A ${ }^{-/-}$LMPPs exhibit increased myeloid potential. The results establish E2A as a key transcription factor directing early lymphoid specification.

40. Mansson R, Hultquist A, Luc S, Yang L, Anderson K, Kharazi S, Al-Hashmi S, Liuba K, Thoren L, Adolfsson $\mathrm{J}$, et al. Molecular evidence for hierarchical transcriptional lineage priming in fetal and adult stem cells and multipotent progenitors. Immunity 2007;26:407-419. [PubMed: 17433729]

41. Rumfelt LL, Zhou Y, Rowley BM, Shinton SA, Hardy RR. Lineage specification and plasticity in CD19- early B cell precursors. J Exp Med 2006;203:675-687. [PubMed: 16505143]

42. Louis I, Heinonen KM, Chagraoui J, Vainio S, Sauvageau G, Perreault C. The signaling protein Wnt4 enhances thymopoiesis and expands multipotent hematopoietic progenitors through beta-cateninindependent signaling. Immunity 2008;29:57-67. [PubMed: 18617424]

43•. Yoshida T, Ng SY, Zuniga-Pflucker JC, Georgopoulos K. Early hematopoietic lineage restrictions directed by Ikaros. Nat Immunol 2006;7:382-391. [PubMed: 16518393]Ikaros-reporter mice were generated, and GFP-expressing LSK progenitors were shown to possess myeloid and lymphoid lineage potentials, but lack erythroid lineage potential. This paper together with earlier work $[2,4-$ 6] established the existence of lymphoid-myeloid progenitors, and further indicated that Ikaros is critical for the proper development of these cells.

44. Sitnicka E, Buza-Vidas N, Ahlenius H, Cilio CM, Gekas C, Nygren JM, Mansson R, Cheng M, Jensen CT, Svensson M, et al. Critical role of FLT3 ligand in IL-7 receptor independent T lymphopoiesis and regulation of lymphoid-primed multipotent progenitors. Blood 2007;110:2955-2964. [PubMed: 17540845]

45. Ikawa T, Kawamoto H, Goldrath AW, Murre C. E proteins and Notch signaling cooperate to promote T cell lineage specification and commitment. J Exp Med 2006;203:1329-1342. [PubMed: 16682500]

46. Zlotoff DA, Schwarz BA, Bhandoola A. The long road to the thymus: the generation, mobilization, and circulation of T-cell progenitors in mouse and man. Semin Immunopathol 2008;30:371-382. [PubMed: 18925398]

47. Liu C, Saito F, Liu Z, Lei Y, Uehara S, Love P, Lipp M, Kondo S, Manley N, Takahama Y. Coordination between CCR7- and CCR9-mediated chemokine signals in prevascular fetal thymus colonization. Blood 2006;108:2531-2539. [PubMed: 16809609] 
48 . Lai AY, Kondo M. Identification of a bone marrow precursor of the earliest thymocytes in adult mouse. Proc Natl Acad Sci U S A 2007;104:6311-6316. [PubMed: 17404232]

49•. Schwarz BA, Sambandam A, Maillard I, Harman BC, Love PE, Bhandoola A. Selective thymus settling regulated by cytokine and chemokine receptors. J Immunol 2007;178:2008-2017. [PubMed: 17277104]These authors demonstrate that CCR9 is expressed on ELPs but not HSCs or MPPs. Upon intravenous injection, CCR9-expressing ELPs cells are more efficient in colonizing the thymus and initiating $\mathrm{T}$ cell development than other progenitor subsets studied. Lai and Kondo further establish that CCR9-expressing ELPs directly home to the thymus in short-term assays.

50. Rossi FM, Corbel SY, Merzaban JS, Carlow DA, Gossens K, Duenas J, So L, Yi L, Ziltener HJ. Recruitment of adult thymic progenitors is regulated by P-selectin and its ligand PSGL-1. Nat Immunol 2005;6:626-634. [PubMed: 15880112]

51. Scimone ML, Aifantis I, Apostolou I, von Boehmer H, von Andrian UH. A multistep adhesion cascade for lymphoid progenitor cell homing to the thymus. Proc Natl Acad Sci U S A 2006;103:7006-7011. [PubMed: 16641096]

52••. Benz C, Martins VC, Radtke F, Bleul CC. The stream of precursors that colonizes the thymus proceeds selectively through the early $\mathrm{T}$ lineage precursor stage of $\mathrm{T}$ cell development. J Exp Med 2008;205:1187-1199. [PubMed: 18458114]By using a combination of lineage-tracing and thymic transplantation, the authors demonstrate that CCR9-expressing ELPs enter the thymus, where they are phenotypically indistinguishable from primitive subsets of ETPs.

53. Perry SS, Welner RS, Kouro T, Kincade PW, Sun XH. Primitive lymphoid progenitors in bone marrow with T lineage reconstituting potential. J Immunol 2006;177:2880-2887. [PubMed: 16920923]

54. Hao QL, George AA, Zhu J, Barsky L, Zielinska E, Wang X, Price M, Ge S, Crooks GM. Human intrathymic lineage commitment is marked by differential CD7 expression: identification of CD7lympho-myeloid thymic progenitors. Blood 2008;111:1318-1326. [PubMed: 17959857] 


\section{Classical Model}

\section{Revised Model}

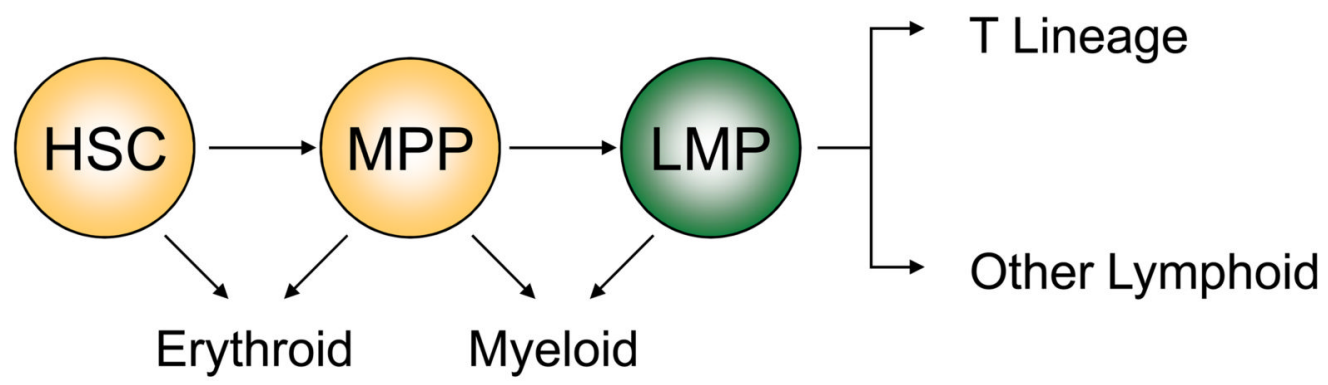

Figure 1. Past and revised models of hematopoiesis

The standard classical model (top) theorized that there is a strict separation of myeloerythroid and lymphoid development. This model proposes that downstream of hematopoietic stem cells (HSC) and multipotent progenitors (MPP) are common myeloid progenitors (CMPs) and common lymphoid progenitors (CLPs). CMPs generate myeloid or erythroid cells while CLPs give rise to lymphoid cells exclusively. This model suggests the thymus is settled by lymphoidrestricted CLPs possessing T, B, and NK lineage potentials, but devoid of non-lymphoid lineage potentials. The revised model (bottom) proposes the existence of lymphoid-myeloid progenitors (LMPs, originally described by Katsura and colleagues [2,3]) as a developmental intermediate in T, B, and myeloid development. Accordingly, this model proposes the thymus is settled by lymphoid-myeloid progenitors with developmental potentials for myeloid, $\mathrm{T}$, and additional cell lineages. 


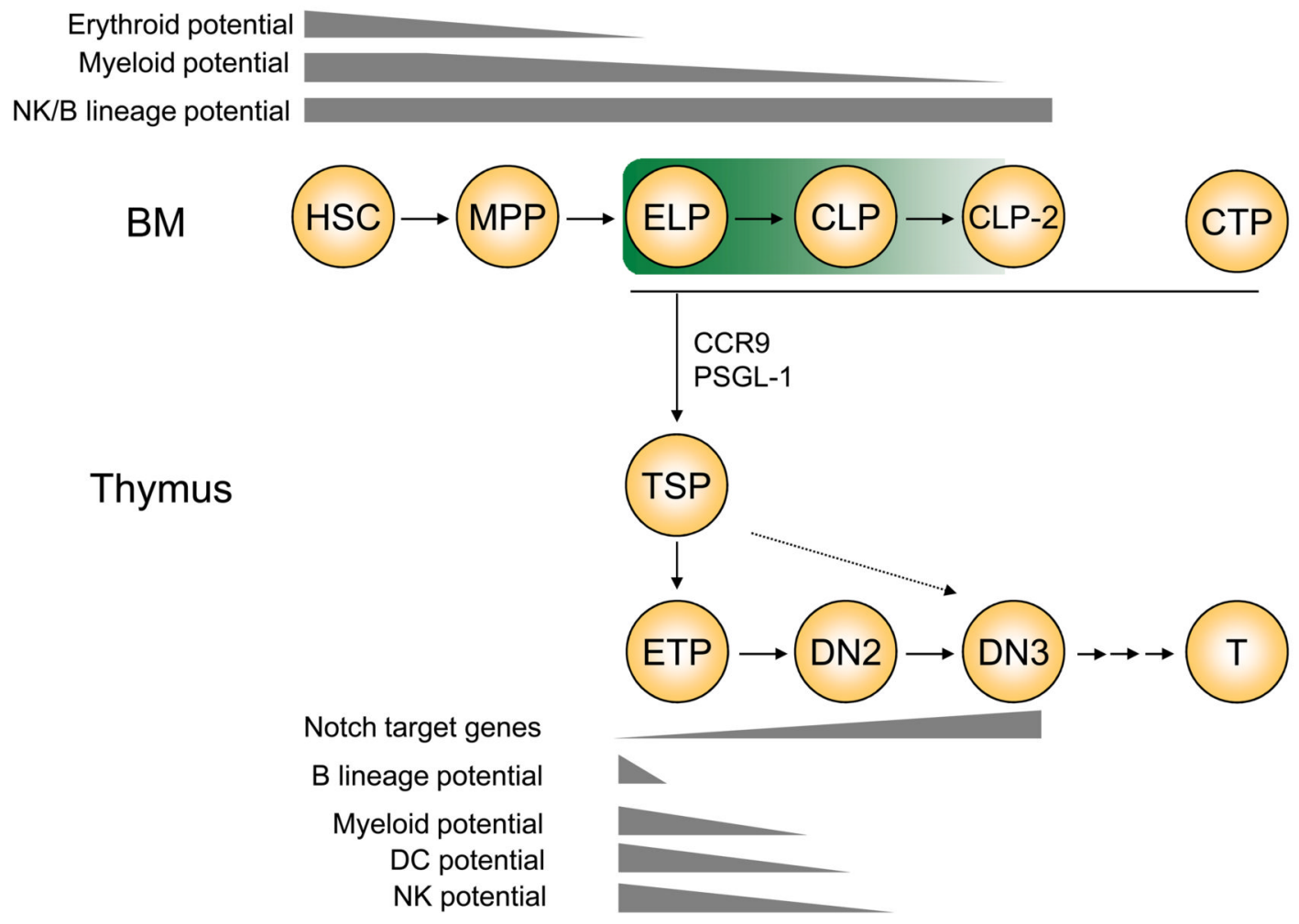

Figure 2. Current view of T lymphocyte development

Progenitors with T cell lineage potential in bone marrow and thymus are depicted. Key nonT cell lineage potentials are indicated at top and bottom in gray. Many progenitor cell types in $\mathrm{BM}$ can respond to Notch1 signaling and so possess T lineage potential. Some of these progenitors share an LSK $\left(\mathrm{Lin}^{-} \mathrm{Sca}-{ }^{+} \mathrm{Kit}^{+}\right)$phenotype, but can be distinguished by surface expression of the Flt3 receptor. They include Flt $3{ }^{-}$LSK populations enriched in hematopoietic stem cells (HSC), Flt ${ }^{\text {low }}$ LSK multipotent progenitors (MPP), and Flt $3{ }^{\text {hi }}$ LSK early lymphoid progenitors (ELP) that also transcribe lymphoid genes such as RAG. Certain progenitors outside the LSK compartment also possess T potential, including

$\mathrm{Lin}^{-} \mathrm{Flt}^{+} \mathrm{IL}^{\mathrm{LR}} \mathrm{R}^{\mathrm{hi}} \mathrm{Kit}^{\mathrm{low}} \mathrm{Sca}-1^{\text {low }}$ common lymphoid progenitors (CLP as well as downstream B220 ${ }^{+}$CLP-2) and committed $\mathrm{T}$ cell progenitors (CTPs). Whereas many cells have $\mathrm{T}$ potential, not all progenitors can home to the thymus effectively. Instead, the ability to home to the thymus is selective, involving molecules such as PSGL-1 and CCR9. While PSGL-1 is not known to be differentially expressed among those BM progenitors described here, CCR9 is first expressed at the ELP stage. Erythroid potential is absent by the ELP stage, but myeloid potential is preserved in ELPs, and likely some CLPs as well as CLP-2 cells. Together, the collective group of ELPs, CLPs, and CLP-2 cells can be regarded functionally as LMPs mentioned in Figure 1, and depicted in green. This group of progenitors is suggested to home to and colonize the thymus as thymus-settling progenitors (TSPs). Consistently, ETPs possess myeloid and lymphoid lineage potentials. As ETPs differentiate into downstream progenitors, cells receive more Notch1 signals, as evidenced by increasing expression of Notch1 target genes.

Concomitantly, the ability to differentiate into alternative lineages is diminished and ultimately lost by the DN3 stage. Note that TSPs may be very heterogeneous. It is possible that some TSPs can bypass the ETP stage. Detailed phenotypes for these progenitor populations have been recently published [36]. 